\title{
Reconstruction of Holocene sea-surface salinity in the Skagerrak-Kattegat: a climatic and environmental record of Scandinavia
}

\author{
HUI JIANG ${ }^{1 *}$, SVANTE BJÖRCK ${ }^{2}$ and NILS-OLOF SVENSSON ${ }^{1}$ \\ ${ }^{1}$ Department of Quaternary Geology, Lund University, Tornavägen 13, S-223 63 Lund, Sweden \\ ${ }^{2}$ Geological Institute, University of Copenhagen, Øster Voldgade 10, DK-1350 Copenhagen K, Denmark
}

Brown III, J., Labéque, K., Paz Villa-Lobos, H. 1998. Reconstruction of holocene sea-surface salinity in the Skagerrak-Kattegat: a climatic and environmental record of Scandinavia. J. Quaternary Sci., Vol. 13, 107-114. ISSN 0267-8179 (No. of Figures: 3. No. of Tables: 2. No. of References: 31)

Received 19 February 1997 Accepted 28 August 1997

\begin{abstract}
Holocene sea-surface salinity in the Skagerrak-Kattegat is reconstructed using weighted averaging regression and calibration (WA) of diatom data from core Skagen 3. Diatom data from surface sediments together with 10-yr mean values of salinity and water temperature were used as a modern training set. Canonical correspondence analysis (CCA) was used to identify statistically significant directions of variation within the training set. The results of forward selection of the environmental variables and associated Monte Carlo permutation tests of the statistical significance of each variable, the canonical coefficients, and the intraset correlations of the environmental variables with the CCA axes suggest that summer and winter sea-surface salinities (SSS, WSS) are potentially reconstructable from fossil diatom assemblages. The changes in sea-surface salinity during the Holocene can be correlated with changes in climate of the circum-Baltic area, the current patterns of the Skagerrak-Kattegat, and the development of the Baltic Sea. Generally low SSS and large differences between WSS and SSS $(\Delta \mathrm{Sw}$-s) during 9000-6000 yr BP might have resulted from a climate with higher precipitation than today in the circum-Baltic area and its catchment, or a climate with maximum precipitation in late spring or early summer. The mechanism behind these patterns may be the combination of the northward shift of the jet stream and a stronger surface westerly penetration into the continent caused by a reduced latitudinal insolation gradient and enhanced land-sea contrast in the early to middle Holocene. It was, however, complicated by local events such as changes in the strength of various currents in the Skagerrak-Kattegat, successions of Baltic brackish and freshwater phases, and hydrodynamic conditions in the circum-Baltic area. (C) 1998 John Wiley \& Sons, Ltd.
\end{abstract}

KEYWORDS: Holocene sea-surface salinity; canonical correspondence analysis (CCA); weighted averaging regression and calibration (WA); diatom; Skagerrak-Kattegat.

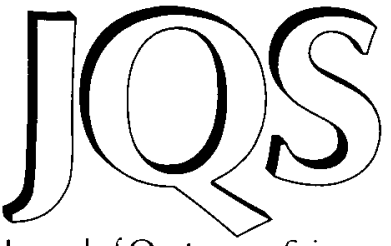

Journal of Quaternary Science

\section{Introduction}

Sea-surface salinity is highly correlated with regional seacurrent patterns. Changes in sea-surface salinity should thus reflect variations in sea-current patterns. The SkagerrakKattegat is hydrographically characterised by the outflow of low saline water of Baltic origin in the southern Kattegat and along the Swedish and the Norwegian coasts, and the inflow of highly saline water from the North Atlantic on the North Jutland Shelf (Fig. 1). The interaction of these two major components determines sea-surface salinity. Based on the variation in freshwater supply of one of the larger rivers

* Correspondence to: Hui Jiang, Department of Earth Sciences, Aarhus University, DK-8000 Aarhus C, Denmark.

Contract grant sponsor: The Swedish Research Council (NFR)

Contract grant sponsor: The Danish Research Council (SNF) to the Baltic Sea and surface salinity measured at Light Vessel Schultz's Grund, southwestern Kattegat, Svansson (1975) concludes that low precipitation in the Baltic Sea and its catchment gives rise to high salinity in the Kattegat. Schott (1966), who carried out Fourier analysis of time series of monthly means of surface salinity, shows that long-term fluctuations of surface salinity in the North Sea can be correlated with fluctuations in river discharge and in precipitation. Although the salinity pattern shows similar behaviour during winter and summer, the salinity in summer is about $2 \mathrm{~g} \mathrm{I}^{-1}$ lower in the surface water entering from the Kattegat, and $1 \mathrm{gl}^{-1}$ lower in the surface water entering from the North Sea than it is in winter (Rodhe, 1992). These results suggest that the outflow of water from the Baltic Sea has a greater influence on changes in sea-surface salinity in the Skagerrak-Kattegat than the inflow of water from the North Sea, in particular during summer. Hence, reconstruction of the sea-surface salinity in the Skagerrak-Kattegat could give 


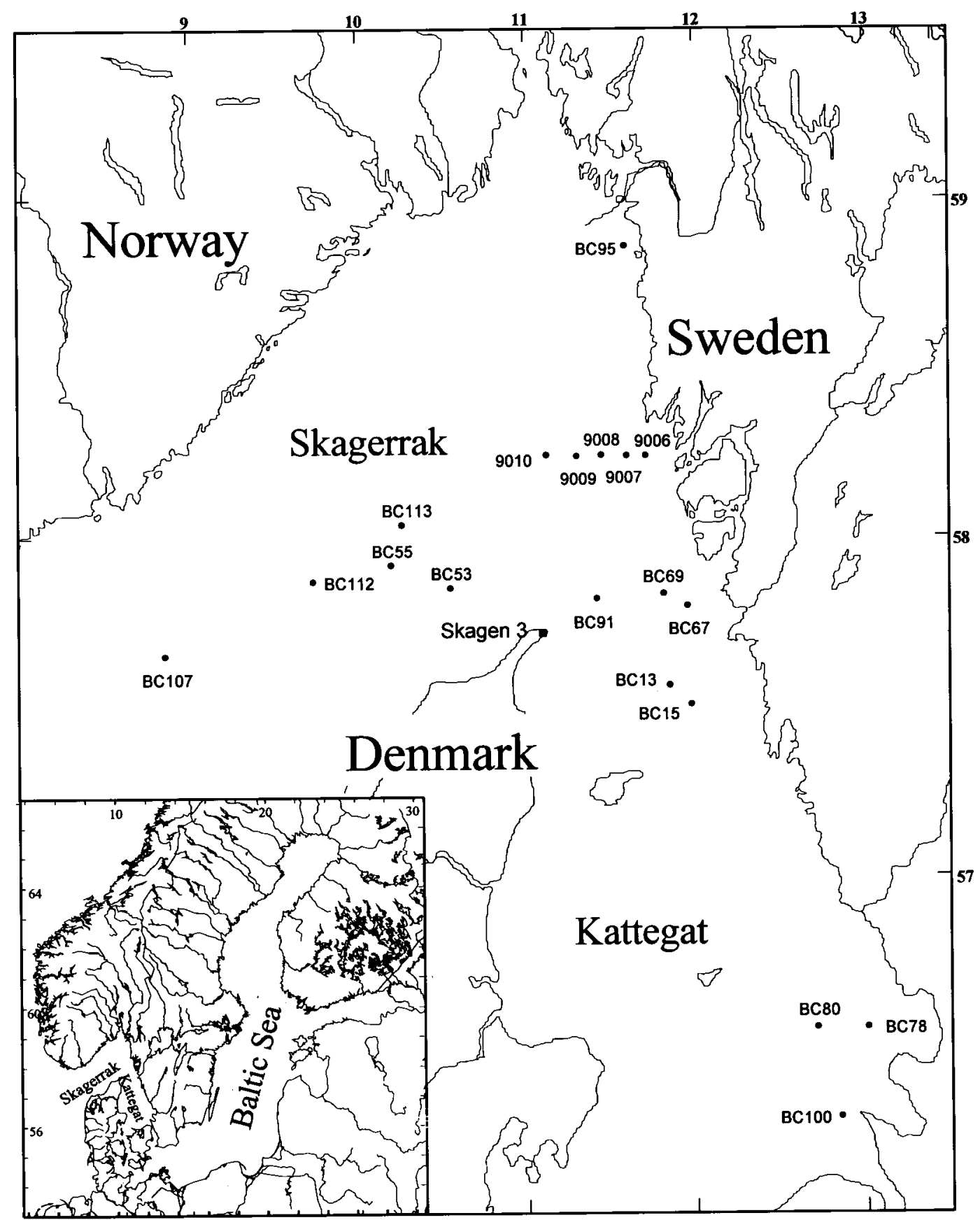

Figure 1 Locations of core sites and the area investigated. Surface sediment cores are marked by bold circles and core Skagen 3 is marked by a bold square.

indications of both modifications in regional hydrography and climatic changes in the neighbouring areas.

Jiang (1996) studied the diatoms from surface sediments of the Skagerrak-Kattegat and their correlation with the spatial changes of environmental variables, such as salinity and temperature. Diatom study on ca. $116 \mathrm{~m}$ of marine sediments in the Skagerrak-Kattegat provides a continuous and detailed palaeoceanographic and palaeoenvironmental record of the last $11000 \mathrm{yr}$ BP in the area (Jiang et al., 1997). In this paper we use diatom data from surface sediments and modern environmental data as a training set to reconstruct the Holocene sea-surface salinity (summer sea-surface salinity, SSS; winter sea-surface salinity, WSS; and differences between winter and summer sea-surface salinity, $\Delta S w$-s) from the Skagerrak-Kattegat.
We expect that chages in WSS during the Holocene most likely reflect variations in the strength of the highly saline water flowing into the Skagerrak-Kattegat, specifically at this site the Jutland current. The SSS is supposed to be strongly reduced by the Baltic Current because the SSS of the Baltic Sea is much lower than in the SkagerrakKattegat, even being totally fresh during the early Holocene (Björck, 1995). The changes in SSS of the SkagerrakKattegat mirror variations in the Baltic outflow, which is controlled by climatic factors in its catchment, mainly precipitation. We draw on observations of modern oceanography and climatology of the region to explain the changes in sea-surface salinity, and further we relate these changes to external climatic factors, including changes in insolation and local hydrodynamic events. 


\section{Material and methods}

\section{Modern data}

Salinity and water temperature data used for the numerical analyses are the mean values for the period 1980-1990 at the surface and bottom of the water column in summer and winter, with a temperature range of between $0.3^{\circ} \mathrm{C}$ and $17.3^{\circ} \mathrm{C}$ and a salinity range of $13.7 \mathrm{~g} \mathrm{I}^{-1}$ to $35.2 \mathrm{~g} \mathrm{I}^{-1}$ (Jiang, 1996). These data were provided by the Oceanographic Laboratory of the Swedish Meteorological and Hydrological Institute. A few data covering the period between 1983 and 1993 were provided by the Geological Survey of Denmark. Nineteen diatom samples from surface sediments with environmental variables were used to develop a modern training set. In total, 117 taxonomic entities were distinguished. Diatom assemblages are dominated by temperate and/or cosmopolitan species. Canonical correspondence analysis (CCA) (ter Braak 1986, 1988, 1990) was used to identify statistically significant directions of variation within these samples. In the first screen of CCA analysis, water depth was excluded because it is almost perfectly correlated with other variables (variance inflation factor, VIF, is larger than 20) (ter Braak 1988, 1990). The VIF values of eight other variables are less than 10, suggesting that each of them makes a unique contribution to the regression equation (Jiang, 1996). After four to five screenings, three to four samples were deleted from palaeo-SSS and palaeo-WSS reconstruction based on the criteria proposed by Birks et al. (1990b), and zero to eleven species were deleted because of their unclear ecological information. This resulted in high root-mean-square error of prediction (RMSEP) in weighted averaging regression and calibration (WA). The eigenvalues for CCA axes 1 and 2 are 0.41 and 0.19 and the speciesenvironment correlations for CCA axes 1 (0.98) and 2 (0.93) are high. Monte Carlo permutation tests (99 unrestricted permutations) indicate that there is only one significant major gradient captured by axis $1(p=0.01)$. The results of forward selection of the environmental variables and associated Monte Carlo permutation tests of the statistical significance of each variable, the canonical coefficients (as judged by an approximate $t$-test, $t$ values larger than 2.1), and intraset correlations of the environmental variables with the CCA axes, show that SSS, WSS, SBT (summer sea-bottom temperature), and WBS (winter sea-bottom salinity) are individually significant $(p=0.01-0.05,99$ unrestricted permutations) and that SSS and WSS are the most important environmental variables, especially SSS. These two environmental variables explain about $37 \%$ of the total variance in the diatom data, of which SSS alone accounts for about $30 \%$. Therefore, these two variables are potentially reconstructable from fossil diatom assemblages.

\section{The fossil data}

Diatom data from core Skagen 3 (Jiang et al., 1997) were used for palaeo-SSS and palaeo-WSS reconstruction purposes (Fig. 1). The samples below $114.9 \mathrm{~m}$ are not included because the diatom assemblages from these samples are totally different from those in the training set, being dominated by sea-ice species. In total, 52 samples from $31.3 \mathrm{~m}$ to $114.9 \mathrm{~m}$ were analysed and they cover the period from ca. 10000-1000 yr BP. The radiocarbon datings (AMS) are from Conradsen and Heier-Nielsen (1995) and are linearly interpolated against core depths (Jiang et al., 1997). A standard marine reservoir correction of $400 \mathrm{yr}$ is subtracted from the dates. Some taxa at core Skagen 3 are absent from the training set and vice versa. Weighted averaging regression and calibration (WA) were used to reconstruct SSS and WSS separately. Classical regression was used to deshrink inferred SSS values and inverse regression to deshrink inferred WSS values because it minimized RMSEP in the training set (Birks et al., 1990a).

In total, 76 species were used as active taxa in the numerical analysis. Seven diatom assemblage zones were distinguished (Table 1). During 10 100-9600 yr BP, temperate and/or cosmopolitan marine littoral species dominated the diatom assemblage. The main species are Cocconeis scutellum var. parva, Cymatosira belgica, Delphineis surirella, and Campylosira cymbelliformis. The diatom assemblage of 9600-8600 yr BP is composed mainly of marine tychoplanktonic species such as Paralia sulcata, Podosira stelliger, and Actinoptychus senarium (Hendey, 1964; Stabell, 1985; Jiang, 1996). Some marine littoral species that tolerate low salinity (e.g. Grammatophora oceanica, Diploneis constrica, and Diploneis suborbicularis) also occur in the zone. Jiang et al. (1997) suggest that the replacement of Cocconeis scutellum var. parva and Cymatosira belgica by Paralia sulcata, Podosira stelliger and Actinoptychus senarius at $9600-8600 \mathrm{yr}$ BP might be a result of the increased influence of currents along the Norwegian and the Swedish west coasts, with relatively lower salinity but higher summer sea-surface temperature. Cocconeis scutellum var. parva and Cymatosira belgica became the main components of the diatom assemblage with increased numbers of Thalassionema nitzschioides at about $8600-7700 \mathrm{yr}$ BP. An abrupt increase in the abundance of Cyclotella striata occurred at $7700 \mathrm{yr} \mathrm{BP}$, which suggests decreasing sea-surface salinity and a strong influence of the coastal currents. At about 5100-2000 yr BP the numbers of marine littoral diatoms, mainly Delphineis surirella and Cymatosira belgica, increase greatly. The abundances of Delphineis surirella may suggest a period of acceleration of the currents along the Danish west coast.

\section{Evaluation of reconstructed SSS and WSS}

Plots of inferred SSS and WSS against observed SSS and WSS (Fig. 2) show a homogeneous scatter over most salinity ranges and residuals are randomly scattered. The inferred SSS values are, however, slightly lower than observed ones, probably because of the lack of sample sites with the highest sea-surface salinity (Jiang, 1996). As the root-mean-square of the error (RMSE) (observed $X_{i}-$ inferred $X_{i}$ ) is invariably underestimated when based solely on the training set, bootstrapping (1000 cycles), a computer-intensive resampling procedure (Birks et al., 1990a), was used to estimate a more reliable RMSEP for the training set. The RMSEP and the rootmean-squares of the two error (RMSE) components $\left(s_{1}, s_{2}\right)$ for the training set are shown in Table 2. The RMSEP values are 2.777 (SSS) and 2.034 (WSS). Sea-surface salinity reconstructed from diatom data of Skagen 3 ranges from about $24 \mathrm{gl}^{-1}$ to $30 \mathrm{~g} \mathrm{I}^{-1}$ for SSS, and $28 \mathrm{~g} \mathrm{I}^{-1}$ to $30.5 \mathrm{gl}^{-1}$ for WSS, with a high fluctuation at about $6000-9000 \mathrm{yr}$ BP. Compared with RMSEP of the modern diatom training set, we think that reconstructed sea-surface salinity can explain large changes in current pattern and major local events, especially SSS. However, it is not suitable for correlating detailed changes in palaeoenvironment. The $s_{1}$ value is small 
Table 1 Developments of palaeoclimate and palaeoceanography since $11000 \mathrm{yr} \mathrm{BP}$ based on diatom and foraminiferal data from Skagen 3 (Conradsen and Heier-Nielsen, 1995; Knudsen et al., 1996; Jiang et al., 1997). Abbreviation of SST is summer sea surface temperature

Diatom zones Climate and oceanography indicated by Foraminiferal zones Climate and oceanography indicated

$\left(\begin{array}{lll}\left({ }^{14} \mathrm{C} y \mathrm{BP}\right) & \left({ }^{14} \mathrm{C} \text { yr BP }\right) & \text { diatoms benthic Foraminifera }\end{array}\right.$

VII (2000-1000) Large influence of the South Trench $\quad A_{1}$ (3300-1000) Current

VIb (3000-2000) Weakening of the South Jutland Current

$\begin{array}{ll}\text { VIa (5100-3000) } & \begin{array}{l}\text { Acceleration of the South Jutland } \\ \text { Current, and relatively low SST }\end{array}\end{array}$

$\mathrm{V}$ (7700-5100) Formation of the South Jutland Current, $\quad A_{3}$ (7600-5500) stronger influence of coastal currents along the Swedish west and Norwegian coasts, and high SST

IV (8600-7700) Strengthening of the North Jutland Current, and possibly relatively low water temperature

III (9600-8600) Higher SST, and stronger influence of coastal currents along the Norwegian and Swedish west coasts

II (10100-9600) An abrupt warming of the sea surface water, and SST exceeded $10^{\circ} \mathrm{C}$
Higher energy conditions, gradually shallower water

Higher energy condition, strengthening of the Jutland Current and climatic cooling

Opening of the English Channel and establishment of the modern circulation pattern

B (8600-7600)

Sediments were derived from a westerly source

C, D (9600-8600)

Major temperature change to boreal condition in the bottom water

$\mathrm{E}_{1,2}(10100-9600) \quad$ Arctic-subarctic marine environment in the bottom water

I (10900-10 100) Cold saline water with SST of about $2{ }^{\circ} \mathrm{C} \quad E_{3}$ (10900-10100) Arctic-subarctic marine environment
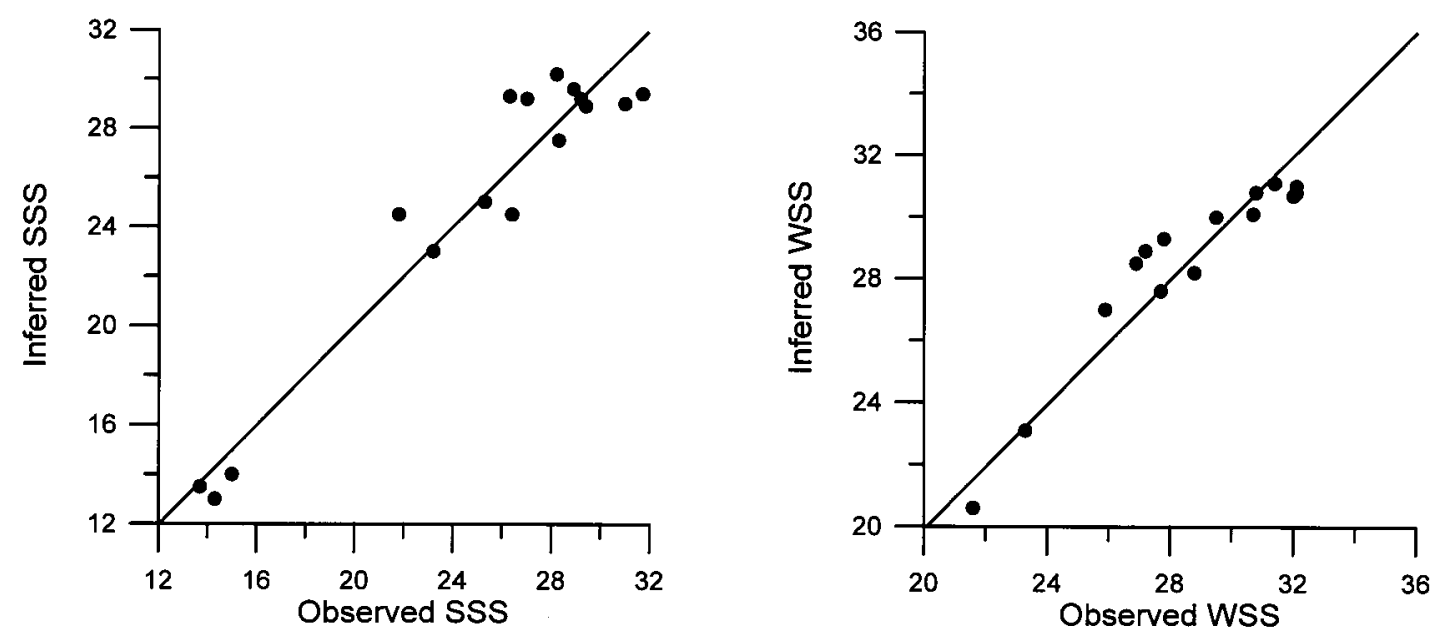

Figure 2 Plots of inferred SSS and WSS against observed SSS and WSS $\left(\mathrm{gl}^{-1}\right)$.

Table 2 Root-mean-square of the error of prediction (RMSE) of the modern diatom training set for SSS and WSS for simple weighted averaging $(\mathrm{WA})$ and tolerance downweighted weighted averaging $\left(\mathrm{WA}_{\text {(tol) }}\right)$ estimated by bootstrapping (1000 cycles) using all taxa

\begin{tabular}{llllllll}
\hline SSS & RMSE prediction & RMSE s & RMSE s & WSS & RMSE prediction & RMSE $s_{1}$ & RMSE $s_{2}$ \\
\hline WA & 2.777 & 1.139 & 2.533 & WA & 2.034 & 0.724 & 1.901 \\
WA $_{\text {(tol) }}$ & 5.025 & 2.749 & 4.206 & WA $_{\text {(tol) }}$ & 2.486 & 1.283 & 2.129 \\
\hline
\end{tabular}

(1.139 SSS, 0.724 WSS) for WA but large (2.749 SSS, 1.283 WSS) for weighted averaging with tolerance downweighting $\mathrm{WA}_{(\mathrm{tol})}$. These RMSE values suggest that the training set is capable of producing reliable estimates of the taxon optima required in WA, but that it is not large enough for reliable estimation of all the taxon tolerances used in $\mathrm{WA}_{\text {(tol) }}$. The second error component $\left(s_{2}\right)$ is invariably larger than the first component and reflects both the considerable natural variation in diatom assemblages at given SSS and WSS, and the fact that very similar assemblages can occur at different SSS and WSS values. 


\section{Interpretation of palaeo-SSS, palaeo-WSS and $\Delta \mathrm{Sw}$-s and discussion}

\section{Regional climate}

Figure 3 shows the Holocene WSS (Fig. 3a), SSS (Fig. 3b) and $\Delta$ Sw-s (Fig. 3c) curves inferred from the fossil diatom assemblages in the Skagen 3 core. The WSS and SSS values have the same distribution patterns during the Holocene with constantly higher values of WSS, which is similar to modern ones, as mentioned above (Rodhe, 1992). The SSS values are generally lower between 9600 and $6000 \mathrm{yr} \mathrm{BP}$, indicating stronger freshwater influence during that period. The $\Delta$ Sw-s values are higher than those of today with high variations between $9600 \mathrm{yr} \mathrm{BP}$ and $6000 \mathrm{yr} \mathrm{BP}$, and slightly lower than or close to the present during the rest of the period (Fig. 3), as modern $\Delta S_{w-S}$ in the area are usually between 1 and $2 \mathrm{~g} \mathrm{I}^{-1}$ (Rodhe, 1992).

On the time-scale of the Holocene, changes in the latitudinal and seasonal distribution of insolation and changes in terrestrial geography must be regarded as boundary conditions controlling climate (Yu and Harrison, 1995). The combined changes in Earth's precession, obliquity, and eccentricity produce changes in the seasonal cycle of solar radiation and, in turn, produce climate changes. Compared with our present regime, the seasonality of solar radiation was considerably greater during the interval from around 12000 to $6000 \mathrm{yr} \mathrm{BP}$, reaching a maximum around 9000 yr BP when solar radiation was greatest in northern summers (Kutzbach and Webb, 1993). Increased summer insolation has been shown by GCM experiments to cause major changes in atmospheric circulation (Kutzbach and Guetter, 1984, 1986; COHMAP Members, 1988), such as a reduced latitudinal insolation gradient in both seasons and enhanced land-sea contrast at all latitudes (Berger, 1978; Harrison et al., 1992). The reduction in the insolation gradi- ent would have resulted in a northward shift of the jet stream (Harrison et al., 1992) and the enhanced land-sea contrast would have resulted in stronger surface westerly penetration into the continent ( $\mathrm{Yu}$ and Harrison, 1995).

Moisture-bearing air currents other than the westerlies enter Scandinavia or parts of it and produce rain or snow at different times of the year. None of these air currents are, however, as moisture-bearing, strong, or persistent as the westerlies and southwesterlies. The precipitation of Scandinavia is, therefore, to a great extent determined by the amounts of water released within these air currents under the influence of topography and, furthermore, by intensities of the air currents. On the whole, mean annual precipitation decreases eastwards in Scandinavia (Wallén, 1970). The stronger surface westerly penetration into the continent, which resulted from the enhanced land-sea contrast, would have produced higher annual precipitation (as both rain and snow) in the circum-Baltic area and, in turn, produced lower sea-surface salinity in the Skagerrak-Kattegat. Furthermore, the variations of the amount of precipitation and temperature during the year, the snow accumulation during the winter, and snow melting in spring exert a strong influence on the hydrology of the rivers and lakes in the Scandinavian countries (Wallén, 1970). In this respect the mountain rivers of Norway and Sweden generally show similar conditions, having a minimum discharge in late summer and winter and a maximum discharge in spring and early summer, as do the rivers in the lowlands of eastern Norway, central Sweden, and Finland. Hence, the higher annual precipitation in the area not only produced lower salinity, in particular SSS, in the Skagerrak-Kattegat but also enlarged the $\Delta$ Sw-s. Dahl and Nesje (1996) studied the Holocene winter precipitation (1 October-30 April) in Hardangervidda, southern Norway and the Scandes Mountains. The mean winter precipitation derived from pine-tree limit data was, in general, high during 9000-5500 yr BP, low between about 5500 and 3000 yr BP, and close to present after $3000 \mathrm{yr} \mathrm{BP}$, which is comparable
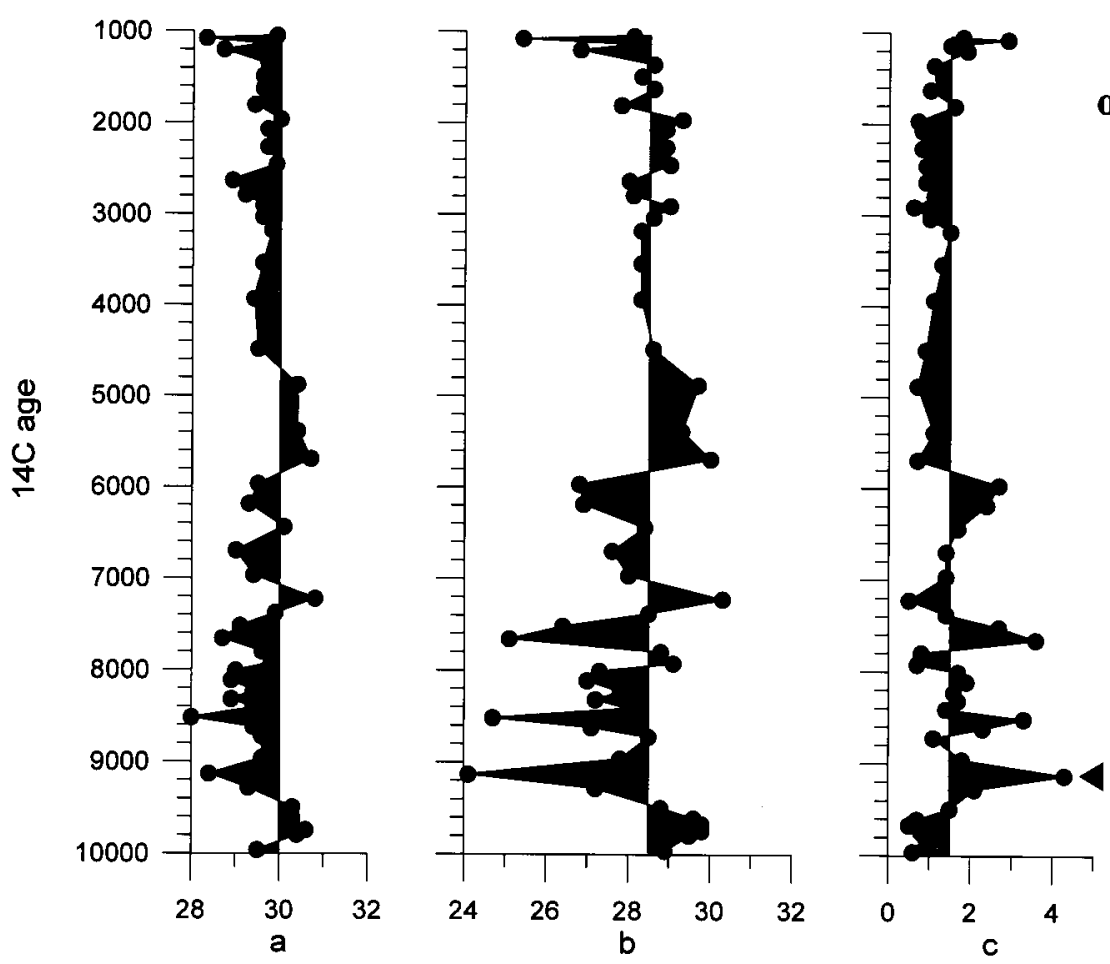

\section{Successions of the Baltic Sea}

\section{Littorina Sea}

Transition

Anlylus Lake

Ancylus drainage

Yoldia Sea

Figure 3 Reconstructed sea-surface salinity $\left(\mathrm{g} \mathrm{I}^{-1}\right)$ are plotted against ${ }^{14} \mathrm{C}$ age for the core Skagen 3: (a) WSS; (b) SSS; (c) $\Delta$ Sw-s. Sea-surface salinity (WSS $=30, \mathrm{SSS}=28.5$ and $\Delta \mathrm{SW}$-s $=1.5$ ) are selected as modern data near the core site. Successions of the Baltic brackish and freshwater phases are also indicated. 
with the sea-surface salinity curve. Based on the study of two species of Lusitanian/Mediterranean ostracods, Vork and Thomsen (1996) also suggest that the temperature maximum of the Atlantic chronozone in southern Scandinavia may be connected to a stronger westerly airflow. There are, however, almost no lake-level data with sufficiently high time resolution from the middle and northern Sweden to test this hypothesis. Furthermore, changes in lake-level are due to changes in the local water budget (the balance of precipitation minus evaporation over lake and its catchment). The strong evaporation would have given rise to low lake levels but would have had less influence on sea-surface salinity, which makes the test even more difficult.

A conspicuous feature in the climate of Europe is the increase in continentality from west to east. Scandinavia is exposed to the prevailing westerly and southwesterly winds of the mean Icelandic low-pressure circulation. The westerly or zonal type of circulation, therefore, is the most frequent one and brings in warm, most Atlantic air over Scandinavia all year, although there is a continuous change, from the zonal to the meridional types of atmospheric circulation throughout the year (Wallén, 1970). In western Europe, the cyclonic type of precipitation is more dominant than further eastwards where the convective type of precipitation gradually becomes of greater significance. As cyclonic activity over western Europe is much more intense in autumn and winter than in summer, the precipitation maximum occurs in these seasons in the Atlantic areas and the western central parts. In the eastern, more continental parts of the region, the dominant convective precipitation gives rise to a maximum in late summer; in southeast Europe the maximum occurs in late spring or early summer. Northward shifts of the jet stream caused by a reduced latitudinal insolation gradient would probably have resulted in a climate similar to that in southeastern Europe, with maximum precipitation in late spring or early summer. Thus, low SSS and high $\Delta$ Sw-s in the Skagerrak-Kattegat could also be explained as a result of such a climate, with maximum precipitation in late spring or early summer. Furthermore, a northward shift of the jet stream would possibly have given rise to higher precipitation in northern Scandinavia, and consequently lowered the sea-surface salinity in the Skagerrak-Kattegat, even if precipitation might be low in southern Scandinavia during some periods. This could probably explain why we have low WSS and SSS in the Skagerrak-Kattegat when lake levels in southern Sweden were low (Digerfeldt, 1988).

\section{Local events}

The Holocene WSS (Fig. 3a), SSS (Fig. 3b), and $\Delta S w$-s (Fig. 3c) data can be further correlated with major local events such as changes in the strength of various currents in the Skagerrak-Kattegat, successions of Baltic brackish and freshwater phases, and hydrodynamic conditions in the circum-Baltic area. High WSS at 9800-9500 yr BP suggests the strong influence of the North Jutland Current. A reduced influence of water of Baltic origin is mirrored by high SSS and low $\Delta$ Sw-s, which generally agrees with the brackish phase of the Yoldia Sea stage, less meltwater from the ice because of relatively cold conditions (Björck, 1995) and the lowest lake levels in southern Sweden (Digerfeldt, 1988). Low SSS between 9500 and $8500 \mathrm{yr}$ BP suggests a strong influence of Baltic water, which is in agreement with the diatom and foraminiferal data (Knudsen et al., 1996; Jiang et al., 1997). The changes in the components of the diatom assemblages at $9600 \mathrm{yr}$ BP suggest stronger influences of the currents along the Swedish west coast and the Norwegian coast, with relatively lower salinity and higher summer seasurface temperature (Jiang et al., 1997). Benthic foraminiferal data from the same core show that a significant temperature change from arctic/subarctic to boreal conditions occurred at about $9600 \mathrm{yr}$ BP in the deeper parts of the SkagerrakKattegat (Knudsen et al., 1996). The idea of warmer summers for northern Europe at about $9000 \mathrm{yr}$ BP is also supported by evidence that taxa requiring warm summers, particularly aquatics, were already present north of their present limits in Scandinavia shortly after $10000 \mathrm{yr}$ BP (Berglund, 1966; Iversen, 1973; Berglund et al., 1984; Kullman, 1995). In addition, some components of the temperate deciduous forest (notably Tilia cordata) were already north of their present limits in the Baltic region by $9000 \mathrm{yr}$ BP (Huntley and Birks, 1983), suggesting that this region too was experiencing summers warmer than at present as early as $9000 \mathrm{yr}$ BP (Huntley and Prentice, 1993). Low SSS values during this period, which are supposed to be a result of high precipitation, however, are inconsistent with low lake levels in southern Sweden (Digerfeldt, 1988). The reasons for this are complicated. Strong evaporation would have given rise to a low lake level but would have had less influence on sea-surface salinity. Northward shift of westerlies would have resulted in decreased precipitation in southern Sweden, but an increase in precipitation in middle and northern Scandinavia (Yu and Harrison, 1995), where most of the Baltic catchment is located. Local hydrodynamic events, such as the rising Ancylus Lake level, created a significant transgression in the southern Baltic at about 9500-9200 yr BP (Björck, 1995), and the associated drainage would have resulted in increased freshwater discharge into the Skagerrak-Kattegat at about 9200 yr BP and consequently lowered WSS and SSS. A large discharge from the Baltic was recorded by a lower seasurface salinity during the period of $7700-5900 \mathrm{yr} \mathrm{BP}$, although the Baltic was brackish during the Littorina Sea stage. It is consistent with diatom, foraminiferal, and lakelevel studies, which suggest larger effects of the Norwegian Coast Current and the currents along the Swedish west coast (Jiang et al., 1997) and a warm and humid climate (Digerfeldt, 1988). The following high salinity period of about $1000 \mathrm{yr}$ must have resulted from a dry climate as indicated by low lake levels (Digerfeldt, 1988), and an acceleration of the South Jutland Current (Jiang et al., 1997). There was no major change in sea-surface salinity until about $1200 \mathrm{yr} \mathrm{BP}$, when a tendency to a gradual decrease in salinity occurred, which parallels the increased lake levels (Digerfeldt, 1988). A short period of high lake levels around 3000-2400 yr BP seems to have been accompanied by a slightly lower sea-surface salinity.

\section{Conclusions}

1. A combination of CCA and WA has been shown to be a good method for quantitative reconstruction of palaeoenvironmental variables in the Skagerrak-Kattegat based on diatom data. Canonical correspondence analysis was used to identify statistically significant directions of variation within the surface samples and to find the most important environmental variables affecting the diatom distribution. Weighted average regression and calibration was used for quantitative reconstruction of palaeoenvironmental variables. 
2. Inferred WSS and SSS were evaluated by observed WSS and SSS, and bootstrapping (1000 cycles), a computerintensive resampling procedure. Root-mean-square error of prediction values are 2.777 (SSS) and 2.034 (WSS). Compared with RMSEP of the modern diatom training set, reconstructed sea-surface salinity could explain large changes in current pattern and major local events, especially SSS, but is not suitable for establishing correlations with detailed changes in palaeoenvironment. The results also show that the training set is adequate for generating reliable estimates of taxon optima required in WA, but that they are not large enough for reliable estimations of all the taxon tolerances used in $\mathrm{WA}_{\text {(tol) }}$.

3. General low SSS and high $\Delta$ Sw-s during 9000-6000 yr BP might have resulted from a climate with either higher annual precipitation than today in the circum-Baltic area, or a climate having maximum precipitation in late spring or early summer. Mechanisms behind this may be a combination of the northward shift of the jet stream and stronger surface westerly penetration into the continent in the early to middle Holocene. This could have been caused by a reduced latitudinal insolation gradient and enhanced land-sea contrast due to increased summer insolation. It was further complicated by local events, such as changes in the strength of various currents in the Skagerrak-Kattegat, successions of brackish and freshwater phases, and hydrodynamic conditions in the circum-Baltic area.

4. The changes in Holocene sea-surface salinity can be correlated with modifications of current patterns in the Skagerrak-Kattegat, development of the Baltic Sea, and lake-level fluctuations in southern Sweden. High WSS and SSS at 9800-9500 and 5700-4700 yr BP show two distinct periods when highly saline water flowed into the Skagerrak-Kattegat, which could be correlated with an acceleration of the Jutland Current. Low WSS and SSS between 9500 and $8500 \mathrm{yr} \mathrm{BP}$ coincide with stronger influences of the currents along the Swedish west coast and the Norwegian coast, along with a warming in the Skagerrak-Kattegat mirrored by diatom and foraminiferal data. This resulted in a significant change in bottom-water temperature in the deeper parts of the Skagerrak-Kattegat.

Acknowledgments We would like to express our gratitude to H. J. B. Birks and two referees for their enthusiasm and valuable comments. B. E. Berglund, G. Digerfeldt and S. P. Harrison critically read the manuscript and we are grateful for their useful comments. Karen Luise Knudsen, Benneth Dennegåard, Marit-Solveig Seidenkrantz, and Kjell Nordberg kindly provided the samples; Lotta Fyrberg and Antoon Kuijpers provided salinity and temperature data; Thomas Persson gave technical support. To all these people we are very grateful. The Swedish (NFR) and the Danish (SNF) research councils are acknowledged for financial support.

\section{References}

BERGER, A. L. 1978. Long-term variations of caloric solar radiation resulting from the Earth's orbital elements. Quaternary Research, 9, 139-167.

BERGLUND, B. E. 1966. Late-Quaternary vegetation in eastern Blekinge, south-eastern Sweden: a pollen-analytical study. II. Postglacial time. Opera Botanica, 12(2), 1-190.

BERGLUND, B. E., LEMDAHL, G., LIEDBERG-JONSSON, B. and PERSSON, T. 1984. Biotic response to climatic changes during the time span 13,000-10,000 B.P.: a case study from SW Sweden.
IN: Mörner, N. A. and Karlén, W. (eds.), Climatic Changes on a Yearly to Millennial Basis, 25-36. D. Reidel, Dordrecht.

BIRKS, H. J. B., JUGGINS, S. and LINE, J. M. 1990a. Lake surfacewater chemistry reconstructions from palaeolimnological data. IN: Mason, B. J. (ed.), The Surface Water Acidification Programme, 301-313. Cambridge University Press, Cambridge.

BIRKS, H. J. B., LINE, J. M., JUGGINS, S., STEVENSON, A. C. and TER BRAAK, C. J. F. 1990b. Diatoms and $\mathrm{pH}$ reconstruction. Philosophical Transactions of the Royal Society of London, Series B, 327, 263-278.

BJÖRCK, S. 1995. A review of the history of the Baltic Sea, 13.08.0 ka BP. Quaternary International, 29, 19-40.

COHMAP MEMBERS 1988. Climatic changes of the last 18,000 years: observations and model simulations. Science, 241, 10431052.

CONRADSEN, K. and HEIER-NIELSEN, S. 1995. Holocene paleoceanography and paleoenvironments of the Skagerrak-Kattegat, Scandinavia. Paleoceanography, 10, 801-813.

DAHL, S. O. and NESJE, A. 1996. A new approach to calculating Holocene winter precipitation by combining glacier equilibriumline altitudes and pine-tree limits: a case study from Hardangerjøkulen, central southern Norway. The Holocene, 6, 381-398.

DIGERFELDT, G. 1988. Reconstruction and regional correlation of Holocene lake-level fluctuations in Lake Bysjön, south Sweden. Boreas, 17, 165-182.

HARRISON, S. P., PRENTICE, I. C. and BARTLEIN, P. J. 1992. Influence of insolation and glaciation on atmospheric circulation in the North Atlantic section: implications of general circulation model experiments for the Late Quaternary climatology of Europe. Quaternary Science Reviews, 11, 283-299.

HENDEY, N. I. 1964. An introductory Account of the Smaller Algae of British Coastal Waters. Part V. Bacillariophyceae (Diatoms). HMSO, London.

HUNTLEY, B. and BIRKS, H. J. B. 1983. An Atlas of Past and Present Pollen Maps for Europe 0-13,000 Years Ago. Cambridge University Press, Cambridge.

HUNTLEY, B. and PRENTICE, I. C. 1993. Holocene vegetation and climates of Europe. IN: Wright, H. E., Jr., Kutzbach, J. E., Webb, T., III, Ruddiman, W. F., Street-Perrott, F. A. and Bartlein, P. J. (eds.), Global Climates since the Last Glacial Maximum, 136169. University of Minnesota Press, Minneapolis.

IVERSEN, J. 1973. The development of Denmark's nature since the last glacial. Danmarks Geologiske Undersögelse, V(7-C), 1-126.

JIANG, H. 1996. Diatoms from the surface sediments of the Skagerrak and the Kattegat and their relationship to the spatial changes of environmental variables. Journal of Biogeography, 23, 129-137.

JIANG, H., BJÖRCK, S. and KNUDSEN, K. L. 1997. A palaeoceanographic and palaeoenvironmental record of the last ${ }^{14} \mathrm{C} 11,000$ years from the Skagerrak-Kattegat, northeastern Atlantic margin. The Holocene, 7, 301-310.

KNUDSEN, K. L., CONRADSEN, K., HEIER-NIELSEN, S. and SEIDENKRANTZ, M.-S. 1996. Paleoenvironments in the SkagerrakKattegat basin in the eastern North Sea during the last deglaciation. Boreas, 25, 65-77.

KULLMAN, L. 1995. Holocene tree-limit and climate history from the Scandes Mountains, Sweden. Ecology, 76, 2490-2502.

KUTZBACH, J. E. and GUETTER, P. J. 1984. The sensitivity of monson climates to orbital parameters changes for 9000 years B.P.: experiments with the NCAR general circulation model. IN: Berger, A., Imbrie, J., Hays, J., Kukla, G. and Saltcman, B. (eds.), Milankovitch and Climate Part 2, 801-820. Reidel, Dordrecht.

KUTZBACH, J. E. and GUETTER, P. J. 1986. The influence of changing orbital parameters and surface boundary conditions on climate simulations for the past 18,000 years. Journal of the Atmospheric Sciences, 43, 1726-1759.

KUTZBACH, J. E. and WEBB, T., III, 1993. Conceptual basis for understanding Late-Quaternary climates. IN: Wright, H. E., Jr., Kutzbach, J. E., Webb, T., III, Ruddiman, W. F., Street-Perrott, F. A. and Bartlein, P. J. (eds.), Global Climates since the Last Glacial Maximum, 5-12. University of Minnesota Press, Minneapolis.

RODHE, J. 1992. Studies of currents and mixing in the Skagerrak. Thesis, Department of Oceanography, University of Göteborg, Sweden. 
SCHOTT, F. 1966. Der Oberflächensalzgehalt in der Nordsee. Deutsche Hydrografische Zeitschrift, Ergänzungsheft, Reihe A, Nr.9, $55 \mathrm{pp}$.

STABELL, B. 1985. Diatoms in Upper Quaternary Skagerrak sediments. Norsk Geologisk Tidsskrift, 65, 91-95.

SVANSSON, A. 1975. Physical and Chemical Oceanography of the Skagerrak and the Kattegat. Report No. 1, 88 pp., Fishery Board of Sweden, Institute of Marine Research, Lysekil, Sweden.

TER BRAAK, C. J. F. 1986. Canonical correspondence analysis: a new eigenvector technique for multivariate direct gradient analysis. Ecology, 67, 1167-1179.

TER BRAAK, C. J. F. 1988. CANOCO-a FORTRAN program for canonical community ordination by (partial) (detrended) (canonical) correspondence analysis, principle components analy- sis and redundancy analysis (version 2.1). Technique Report LWA88-02, 95 pp. Groep Landbouwwiskunde, Wageningen.

TER BRAAK, C. J. F. 1990. Update notes: CANOCO version 3.10, 35 pp. Agricultural Mathematics Group, Wageningen.

VORK, K. A. and THOMSEN, E. 1996. Lusitanian/Mediterranean ostracods in the Holocene of Denmark: implications for the interpretation of winter temperatures during the postglacial temperature maximum. The Holocene, 6, 423-432.

WALLÉN, C. C. (ed.) 1970. Climates of Northern and Western Europe. Elsevier, Amsterdam.

YU, G. and HARRISON, S. P. 1995. Holocene changes in atmospheric circulation patterns as shown by lake status changes in northern Europe. Boreas, 24, 260-268. 